\title{
On Latin nominal inflection: the form-function relationship
}

\author{
Bernd Wiese
}

\begin{abstract}
The present paper provides a new approach to the form-function relation in Latin declension. First, inflections are discussed from a functional point of view with special consideration to questions of syncretism. A case hierarchy is justified for Latin that conforms to general observations on case systems. The analysis leads to a markedness scale that provides a ranking of case-number-combinations from unmarked to most marked. Systematic syncretism always applies to contiguous sections of the case-number-scale ('syncretism fields'). Second, inflections are analysed from a formal point of view taking into account partial identities and differences among noun endings. Theme vowels being factored out, endings are classified on the basis of their make-up, e.g., as sigmatic endings; as containing desinential (non-thematic) vowels; as containing long vowels; and so on. The analysis leads to a view of endings as involving more basic elements or 'markers'. Endings of the various declensions instantiate a small number of types, and these can be put into a ranked order (a formal scale) that applies transparadigmatically. Third, the relationship between the independently substantiated functional and formal hierarchies is examined. In any declension, the form-function-relationship is established by aligning the relevant formal and functional scales (or 'sequences'). Some types of endings are in one-to-one correspondence with bundles of morphosyntactic properties as they should be according to a classical morphemic approach, but others are not. Nevertheless, endings can be assigned a uniform role if the form-function-relationship is understood to be based on an alignment of formal and functional sequences. A diagrammatical form-function relationship is revealed that could not be captured in classical or refined morphemic approaches.
\end{abstract}

Keywords Latin · Inflectional morphology · Case $\cdot$ Syncretism

B. Wiese ( $\square)$

Institut für Deutsche Sprache (IDS), Postfach 1016 21, 68016 Mannheim, Germany

e-mail: wiese@ids-mannheim.de 


\section{Introduction}

How are the morphosyntactic features of word forms signalled in a flexive (or 'fusional') linguistic system by the make-up of forms? Taking up this question I would like to present a case study, viz. a study of the declensions of Classical Latin (Latin, for short). Latin nominal inflection provides a standard example of a complex morphological system that exhibits a cluster of properties characteristic of flexive morphology. This concerns most prominently the existence of homonymous, synonymous and cumulative morphological exponents the distribution of which depends on classifications of nouns for gender and declension class (Plank 1991a). ${ }^{1}$

Morpheme-based analyses (as, e.g., in Householder 1947) hardly offer any insight into the 'logic' of flexive systems. Various approaches provide techniques that help to reduce the variety of surface forms (e.g., by postulating abstract underlying forms or by usage of morphophonological rules). However, the fact remains that the Latin system does not conform to the expectations of a morphemic perspective. A conception that construes inflectional endings as 'Saussurean symbols' does not turn out as fruitful here (Matthews 1991: 174). Traditional accounts within word-and-paradigm morphology, while doing little more than listing forms nonetheless point out the way to a non-symbolic notion of morphological marking. Consider the stance taken by de Saussure (1976: 122) in his discussion of German plural marking: "ce n'est pas 'Gäste' qui exprime le pluriel, mais l'opposition 'Gast: Gäste',". From this point of view, morphological marking is not a matter of 'exponents' that stand for 'exponenda' but of distinguishing word forms that serve for distinct functions. Thus, functional distinctions are expressed by being correlated with formal distinctions. Applying this line of thought to Latin nominal inflection, I shall investigate (i) the functional distinctions to be expressed, (ii) the expressive means used for formal differentiation, and (iii) the nature of the correlation between the two. The paper is organised as follows.

On the functional side, I shall consider the structure of the system of declensions as well as the structure of the case system relying on results of typological research as summarised in Blake (2001) (Sect. 2). The functionally characterised positions (casenumber-combinations) to be filled in inflectional paradigms are placed on a ranked order (or functional sequence) determined on this basis. On the formal side, I shall be looking closely at partial identities and differences amongst endings (Sect. 3). The analysis shows that endings may be construed as combining a small number of basic components (or 'markers') and, on this basis, may be ranked in terms of relative degrees of markedness. The resulting form-based hierarchy (or formal sequence) among types of Latin nominal endings will turn out to be at the very foundation of the form-function-relationship.

\footnotetext{
${ }^{1}$ This paper was presented at the 24. Jahrestagung der Deutschen Gesellschaft für Sprachwissenschaft, March 2002; at the Colloquium des Graduiertenkollegs "Universalität und Diversität: Sprachliche Strukturen und Prozesse", University of Leipzig, December 2006; and at a workgroup during the 3rd meeting of the Network Core Mechanisms of Exponence, Großbothen June 2008. I would like to thank the audiences for stimulating feedback. I am especially grateful to Hardarik Blühdorn, Gereon Müller, Adriano Murelli, Jochen Trommer, and Gisela Zifonun for helpful comments and discussion.
} 
Finally, the relationship between the independently substantiated functional and formal hierarchies will be examined (Sect. 4). The literature often indicates a general tendency towards a diagrammatical (or 'iconic') correlation of formal and functional complexity (Jakobson 1965; Primus 1993). Regarding Latin nominal inflection, Householder found "a crude correspondence between complexity of function and length of ending" (1947: 48). The mere reference to the length of suffixes (as given by the number of phonemes) is, however, insufficient. In the analysis presented here, the diagrammatical form-function correlation can be clarified.

The prima facie confusing diversity of dependencies and interconnections within the inventory of Latin noun endings discussed in detail by Risch (1977: 236, "Abhängigkeiten und Querverbindungen") gives way to a simple alignment of formal and functional sequences that have been established independently. Section 5 adds a short conclusion. ${ }^{2}$

\section{Functional categories}

\subsection{Latin noun paradigms}

Traditional presentations of Latin noun inflection make use of paradigms which are grouped into five declensions. Declensions may be identified using the classical numbering as in Table 1. Alternatively, reference may be made to theme vowels characteristic of declensions, hence ' $a$-declension', ' $o$-declension', etc. or 'consonantal declension ( $C$-declension)', in the absence of a theme vowel. In this case a subdistinction within the 3 rd declension may be assumed between the $i$-declension and the consonantal declension. As a result of a long process of interaction, these two declensions have largely merged in Classical Latin but a number of variants (two of which are presented in the table) may still be distinguished (see Sect. 4, below).

For present purposes, the multitude of variants, deviations and special cases in Latin declension may largely remain outside the scope of consideration. In what follows, I shall focus on the standard paradigms given in Table 1. The selection of paradigms and the listing of inflectional forms follows Risch (1977: 231), who provides a most careful discussion of the noun endings of Classical Latin, both from a synchronic and from a diachronic perspective. ${ }^{3}$

Declensions may be grouped according to gender and word class. Nouns of the 1st and 5th declensions are mostly feminine; those of the 2nd and 4th declensions

\footnotetext{
${ }^{2}$ The following abbreviations will be used: A (accusative), Ab (ablative), D (dative), G (genitive), N (nominative), $\mathrm{V}$ (vocative); Ntr (neuter); Sg (singular), Pl (plural).

${ }^{3}$ Risch's presentation accords with the "Normalparadigmen" in Leumann's Formenlehre (Leumann 1977: $417,423,430,441,444)$, the standard reference work in Latin morphology. However, Risch prefers a system of six declensions ("die fünf oder besser sechs lateinischen 'Deklinationen' ") (Risch 1977: 229) splitting up the 3 rd declension into 3A (consonantal declension) and 3B ( $i$-declension). Word forms appear in orthographic notation (except for $r \bar{e} g s$, which would be $r \bar{e} x$ ); long vowels are marked by macrons. (For more details concerning vowel quantity see Sect. 3.2, below.)
} 
Table 1 Latin noun paradigms

\begin{tabular}{|c|c|c|c|c|c|c|c|}
\hline & & $\begin{array}{l}\text { 1st dec. } \\
(a \text {-dec. })\end{array}$ & $\begin{array}{l}\text { 2nd dec. } \\
\text { (o-dec.) }\end{array}$ & $\begin{array}{l}\text { 3rd dec. } \\
(i \text {-dec. })\end{array}$ & $\begin{array}{l}\text { 3rd dec. } \\
\text { ( } C \text {-dec.) }\end{array}$ & $\begin{array}{l}\text { 4th dec. } \\
\text { (u-dec.) }\end{array}$ & $\begin{array}{l}5 \text { th dec. } \\
(\bar{e}-\text { dec. })\end{array}$ \\
\hline \multirow[t]{6}{*}{$\mathrm{Sg}$} & $\mathrm{V}$ & capra & lupe & ignis & $r \bar{e} g s$ & ictus & $d i \bar{e} s$ \\
\hline & $\mathrm{N}$ & capra & lupus & ignis & $r \bar{e} g s$ & ictus & $d i \bar{e} s$ \\
\hline & A & capram & lupum & ignem & rēgem & ictum & diem \\
\hline & $\mathrm{Ab}$ & caprā & lup $\bar{o}$ & $i g n \bar{l}$ & $r \bar{e} g e$ & $i c t \bar{u}$ & $d i \bar{e}$ \\
\hline & $\mathrm{D}$ & caprae & lupō & $i g n \bar{\imath}$ & $r \bar{e} g \bar{\imath}$ & $i c t u \bar{l}$ & diei \\
\hline & G & caprae & $\operatorname{lup} \bar{\imath}$ & ignis & rēgis & $i c t \bar{u} s$ & diei \\
\hline \multirow[t]{4}{*}{$\mathrm{Pl}$} & $\mathrm{V} / \mathrm{N}$ & caprae & lup $\bar{\imath}$ & ignēs & $r \bar{e} g \bar{e} s$ & $i c t \bar{u} s$ & diēs \\
\hline & A & caprās & lupōs & ignīs & $r \bar{e} g \bar{e} s$ & $i c t \bar{u} s$ & $d i \bar{e} s$ \\
\hline & $\mathrm{Ab} / \mathrm{D}$ & caprīs & lupīs & ignibus & rēgibus & ictibus & diēbus \\
\hline & G & caprārum & lupōrum & ignium & rēgum & ictuum & diērum \\
\hline Ntr Sg & VNA & - & iugum & mare & nōmen & gепи & - \\
\hline Ntr Pl & VNA & - & iuga & maria & nōmina & gепиа & - \\
\hline
\end{tabular}

are mostly non-feminine, i.e. masculine or neuter. ${ }^{4}$ In contrast, the 3 rd declension comprises nouns of all genders. Thus, regarding gender, I distinguish declensions of the non-feminine type $(-\mathrm{F})$, of the feminine type $(+\mathrm{F})$, and of the indifferent type $( \pm F)$. As a rule, neuters show the same endings as masculines except for the vocative/nominative/accusative singular and plural (therefore, with neuters only forms of these cases are exemplified in Table 1).

Latin nominal inflections apply to nouns and adjectives, but not equally. Two groups of declensions may be distinguished, those that are restricted to nouns and those that apply to adjectives as well. The 4th and 5th declensions, which do not comprise adjectives, belong to the former type (pure 'nominal declensions'). The 1st and 2nd declensions belong to the latter type ('(co-) nominal declensions'): they comprise both nouns and adjectives, and adjectives and nouns show the same sets of endings distributed according to gender. The 3 rd declension, too, comprises both nouns and adjectives but the sets of endings used with nouns and adjectives are not strictly identical. If a subdistinction is made between $i$-declension and $C$-declension it may be noted that adjectives mostly follow the $i$-declension while the $C$-declension pattern is restricted for the most part to nouns. ${ }^{5}$ Thus, to simplify somewhat, the $i$-declension falls into the group of (co-)nominal declensions, while the $C$-declension belongs to the pure nominal type.

Following Risch (1977), Table 1 is set up so that cells occupied by identical forms are placed next to one another if possible. For this reason, cases are given in the order

\footnotetext{
${ }^{4}$ Exceptions (Leumann 1977: 417, 422, 411, 444) include $a$-declension masculines such as poēta, scrība, nauta, and $o$-declension feminines, e.g., proper nouns/greek loanwords like dialectus, diphthongus, Aegyptus, Corinthus and names of trees like alnus, fägus, pōpulus, and a few others. There are also some feminines like manus which belong to the 4th declension and one masculine (diess) in the 5th declension.

${ }^{5}$ Note that comparatives follow the $C$-declension; otherwise adjectives of the $C$-declension are rare (Leumann 1977: 437f.). See also footnote 20, below.
} 
V-N-A-Ab-D-G. ${ }^{6}$ Insofar as such identities of form are not arbitrary they should be accounted for by a proper treatment of the morphological system, of course.

\subsection{The system of cases}

As pointed out in Greenberg (1966: 38), the principal division to be made in the system of Latin cases (as well as in other case systems) is based on the distinction between direct cases (vocative, nominative, accusative) and oblique cases (ablative, dative, genitive) where direct cases are assumed to constitute an unmarked category in relation to the oblique. To stress this relation, I shall refer to direct cases as nonoblique cases. The relevance of the non-oblique/oblique distinction for Latin is particularly apparent in the neuter gender: the forms of the three non-oblique cases always coincide in the singular and also in the plural. Moreover, in the oblique cases, the endings of neuter nouns are identical to those of masculine nouns (allowing for minor variation). This fact is adduced by Greenberg to support the unmarked status of the non-oblique cases. A second relevant typological fact Greenberg refers to is that direct cases as against oblique cases may often show 'zero expression' (as does the nominative in languages like Turkish). As for Latin, forms without endings appear as non-oblique forms of neuters (such as nomen). Otherwise, Latin nouns of the standard paradigms show endings in forms of all cases. ${ }^{7}$ However, as will be shown below, a number of forms that do have endings may be analysed as instances of 'zero expression' of case given a suitable notion of morphological marker.

The non-distinctness of cases in the non-oblique neuter as well as the nondistinctness of masculine and neuter in the oblique cases may be addressed as clear instances of (systematic) syncretism as opposed to (accidental) homonymy. A general discussion of the difference between systematic vs. accidental instances of non-distinctness of forms or endings would be beyond the scope of this paper; see Carstairs (1987: Ch. 4.2.2) and Baerman et al. (2005). However, mention should be made of at least one morphological property of patterns of non-distinctness that can be a strong indicator of systematic syncretism, termed 'regularity' in Baerman et al. (2005: 23). When a pattern of non-distinctness is not bound to the morphological material involved this may suggest that the non-distinctness is systematic. The vocative-nominative-accusative syncretism found with neuters is a case in point. This syncretism is a uniform system-wide phenomenon as it encompasses singular and plural subparadigms of different declensions. As it appears independently of the different endings that are involved (and even in the absence of endings) non-distinctness is not likely to be due to 'phonological accidents'.

\footnotetext{
${ }^{6}$ For a detailed investigation of the assumption that paradigms could be linearly (or perhaps circularly) ordered so that formally non-distinct word forms appear in adjacent positions, based on various IndoEuropean languages, see Plank (1991b). As for Latin, Plank gives the same order of cases as Risch, though amended by a loop, referring back from the genitive to the nominative. As Plank emphasises, some unexpected patterns of syncretism may turn out to be "isolated, superficial, and local" (p. 185). The nominative/genitive homonymy in the singular of the paradigm of ignis provides a case in point (cf. Sect. 3.2, below). See also Johnston (1997: Sect. 2.2.8).

${ }^{7}$ Under restricted conditions, in particular if stems end in sonorants, vocative/nominative forms may lack the usual endings (cf., e.g., puer, 2nd dec., pater, homō, 3rd dec.). For details see Leumann (1977, 423, $433-4)$.
} 


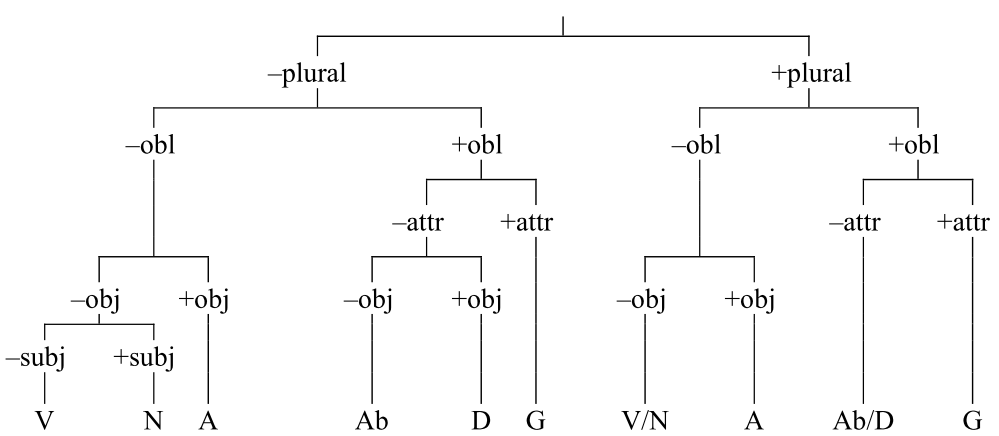

Fig. 1 Case distinctions in singular and plural

The division between non-oblique and oblique cases in Latin is clear-cut. There are no instances of systematic syncretism that involve non-oblique and oblique case forms of the same number. However, inside these groups of cases syncretisms abound. ${ }^{8}$ Most oblique subparadigms, i.e., subparadigms comprising the three cases ablative, dative, and genitive, differentiate not more than two case forms, and the same is true of non-oblique subparadigms.

In the plural, this obtains throughout. As is often the case, in the marked number differentiation of cases is severely reduced (cf. Greenberg 1966: 27). The systematic reduction of case differentiation in the plural as compared to the singular can be accounted for straightforwardly if case systems are regarded as hierarchical classification systems. A case-number hierarchy for Latin is given in Fig. 1 that extends the partial analysis in Williams (1981: 267f.). ${ }^{9}$ (In Fig. 1, '-obl' stands for 'nonoblique', '+obl' stands for 'oblique' etc.)

From a typological point of view, cases may be characterised by reference to their primary syntactic functions. As Greenberg notes, in the passage referred to above (1966: 38), case systems typically include cases of the subject and of the object as well as a possessive case, or, as I shall put it, an attributive case. Thus, as indicated in Fig. 1, the genitive may be identified as an attributive case while the accusative may be identified as an objective case.

In the oblique plural, only the genitive receives distinct marking while ablative and dative coincide throughout declensions. This is, of course, another standard case of systematic syncretism (and it is analysed as such, e.g., in Carstairs 1987: 93). In a hierarchical system as proposed here, this syncretism can be taken care of if the attributive case (genitive) is opposed to the remaining oblique cases (dative and ablative), which are, then, 'non-attributive'. Non-attributive cases split into dative and

\footnotetext{
${ }^{8}$ This constellation fits into the general typology of syncretisms established in Baerman et al. (2005). See also Plank (1991b: 190) on the relevance of the grouping nominative/accusative vs. local/adverbial cases/dative for (non-) syncretism.

${ }^{9}$ The analysis in Williams (1981) excludes both vocative and genitive and is insufficient as it stands, as argued in Baldi (1983) and Joseph and Wallace (1984). The present proposal evades the objections raised against Williams' approach. Mutatis mutandis, the case hierarchy presented in Fig. 1 applies also to related languages such as Russian and Polish; see Wiese (2004, 2011). For a somewhat different hierarchy encompassing the six Latin cases see Johnston (1997: 183).
} 
ablative, as visible in subparadigms of the singular. Adapting a suggestion of Bierwisch (1967), the dative may be characterised as an oblique objective case. ${ }^{10}$ This leaves the ablative that can be used for various oblique functions as long as these are not covered by the more specific cases genitive or dative. The variety of functions distinguished in traditional grammars is telling: ablativus sociativus, respectus, qualitatis, instrumentalis, loci, separativus, comparationis, temporis etc. Diachronically, the Latin ablative unites the functions of the Indo-European cases instrumental, locative and ablative proper (or separative) and maybe others (Gasperini 1999). Moreover, for the most part, it is used as a prepositional case. The traditional but somewhat misleading name of the case should not detract from the fact that the Latin ablative is what Blake (2001: 157f.) has called an 'elsewhere case', that is a case that is used for a broad spectrum of functions that do not fall into the domains of more specialised cases. The Latin ablative may be aptly characterised as a general oblique case as suggested by Blake's label 'abl/obl' (2001: 158) or as the unmarked oblique case (Johnston 1997: 184).

In the non-oblique plural, only the accusative may receive distinct marking while vocative and nominative coincide throughout declensions. Even in the singular a distinction between vocative and nominative is made only in the $o$-declension (but not with neuters, of course). Again, this is a case of systematic syncretism that reflects relations of markedness within the declensional system (Greenberg 1966: 27). As indicated in Fig. 1, this syncretism can be taken care of if the objective case accusative is opposed to the remaining non-oblique cases (vocative and nominative), which are, then, 'non-objective'. Non-objective cases split into vocative and nominative as visible in the paradigm of lupus. The nominative can be characterised as the subjective case as usual. The vocative then turns out to be a case 'without features'. This agrees with the fact that the vocative as a case of address differs from other cases with respect to the syntactic-semantic role it serves to signal: the vocative unlike other cases does not indicate a relationship between the respective nominal and a head it depends on (Blake 2001: 8). Rather, as Jakobson put it, "address in the vocative stands outside the grammatical sentence" (Jakobson 1984: 7). This characteristic finds a natural reflection in the well-known preference for vocatives to show 'zero expression'.

The case hierarchy proposed for Latin is in line with general observations about differentiation in case systems as established in Blake (2001: 155-160). Blake sets aside the vocative on account of its functional peculiarity. Apart from the vocative Latin possesses a system of five cases that fits into a pattern of regularly increasing

\footnotetext{
${ }^{10}$ Bierwisch (1967) offers a decompositional analysis of the four-case-system of Modern German, using three features, Gov(erned), Obl(ique), and Gen(itive), where dative and genitive are $+\mathrm{Obl}$, accusative and dative are + Gov, and genitive is + Gen. A feature based-analysis could also be proposed for Latin cases. An analysis based on a minimal feature system - three features for six cases-is possible when one takes advantage of the oft-observed parallelisms between nominative and genitive, e.g., the fact that the nominative serves as a subject case in active and passive sentences while the genitive serves as a subiectivus and as an obiectivus. One might consider, then, that there is a case feature, say Subj(ect), that is shared by nominative and genitive. The genitive would be the oblique subjective case, the nominative the non-oblique subjective case. For Latin we would get, then, the following feature specifications of cases: vocative (none), nominative (+Subj), accusative (+Gov), ablative $(+\mathrm{Obl})$, dative $(+\mathrm{Obl},+\mathrm{Gov})$, genitive $(+\mathrm{Obl},+$ Subj). For application and some discussion of such a feature system see Müller (2004) and Alexiadou and Müller (2008).
} 
complexity in comparison with systems that possess a lesser number of cases. Consider Modern Greek as a typical three case system. As confirmed by Blake, systems of three cases usually comprise a nominative, an accusative, and a genitive-oblique, thus a general oblique case or 'elsewhere case' whose functions include those of a genitive. A typical example of a system of four cases would be Ancient Greek that has a nominative, an accusative, a genitive and a dative-oblique, the dative-oblique (called 'dative' in grammars of Ancient Greek) being the 'elsewhere case'. Latin, as presented by Blake, has a nominative, an accusative, a genitive, a dative, and an ablative-oblique. Note also that the reduced plural system of Latin conforms to the pattern given by Blake as typical for four case systems, dative and ablative being merged. Of course, the functions of cases from different languages that go by the same name must not naïvely be taken to be identical. However, the typological findings (confirmed in Kulikov 2006) clearly support the structure of the Latin case system assumed above.

Thus, within a hierarchical system of classifications the oblique domain may be left undivided (as in Modern Greek where the general oblique case is called genitive). Or, if the oblique domain is subdivided at all, the first subdivision should typically single out a genitive as a specific case opposed to a general oblique (called dative in the grammar of Ancient Greek or, say, Modern German). If there is a further subdivision of the remaining domain it is expected that a dative will be singled out as a specific case opposed to a more restricted oblique elsewhere case (the latter being called ablative in Latin grammar). As a result, we obtain the hierarchy of the oblique cases displayed in Fig. 1.

\subsection{Syncretism fields}

In Fig. 1, unmarked categories appear to the left, marked categories appear to the right. The twelve case-number-combinations that are constitutive of Latin noun paradigms are positioned on a scale of markedness, with vocative singular on the least marked end and genitive plural on the most marked end. As will be shown, in cases of systematic syncretism it is always neighbouring positions on the casenumber-scale that are collapsed, or more generally, contiguous sections of the scale. I shall refer to such contiguous sections of non-distinctness as 'syncretism fields' adopting a term from Bierwisch (1967: 245f.). System-wide syncretism as discussed above provides cases in point (syncretism of ablative and dative in the plural, of vocative and nominative in the plural, and of vocative, nominative, and accusative in the singular and in the plural of neuters). Additional syncretisms apply to subsets of the set of declensions as shown in Fig. 2.

The arrangement of declensions in Fig. 2 reflects the grouping in terms of correlations between declension class membership and gender as well as parts of speech, which have been discussed in Sect. 2.1, above. This is indicated on the left-hand side of the figure. The adjacent columns list the endings of the non-oblique cases of the singular. Further endings belonging to each declension can be found by following the lines connecting the columns.

In the plural, there is syncretism of the nominative and accusative in the $u-, C$-, and $\bar{e}$-declensions, i.e., in those declensions restricted to nouns in the typical cases 
$\begin{array}{llllllllllllllllll} & \text { I } & \text { N } & \text { G } & \text { U } & \text { L } & \text { A } & \text { R }\end{array}$

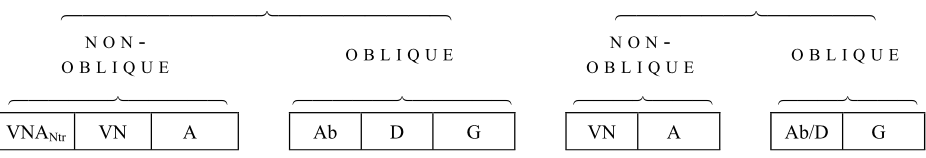

P L U R A L
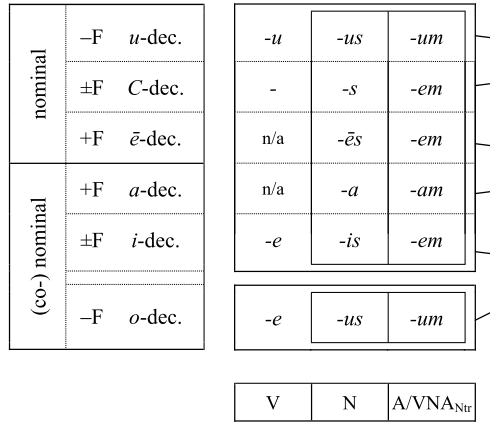

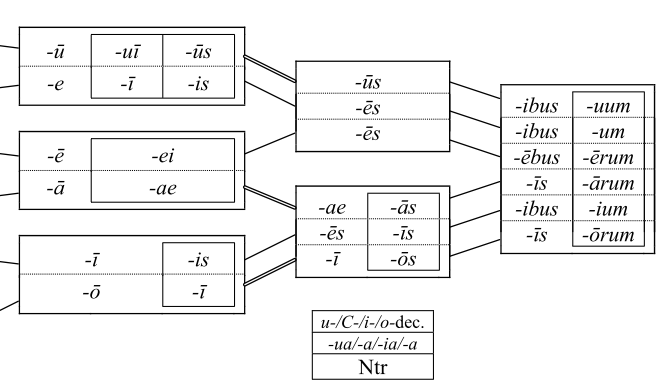

$=\mathrm{G}_{\mathrm{Sg}}=\mathrm{VN}_{\mathrm{Pl}}$

Fig. 2 Syncretisms in Latin declensions

while both cases are kept formally distinct in the $a-, i$-, and $o$-declension, i.e., in those declensions that are typically used also for adjectives. While the syncretism of nominative and accusative plural is not system-wide, it is still regular in the sense of Baerman et al. (2005). The same is true of the syncretisms found in the oblique cases of the singular. Oblique singular subparadigms display three types of differentiation. In the $u$ - and $C$-declensions the three oblique cases (ablative, dative, genitive) are formally distinguished. The $+\mathrm{F}$-declensions ( $a$-, $\bar{e}$-declensions) show syncretism of dative and genitive whereas the remaining declensions (o-, $i$-declensions) show syncretism of ablative and dative. In the non-oblique singular, the $o$-declension displays a special pattern, in which the ending -um serves for vocative/nominative/accusative neuter word forms as well as for non-neuter accusative word forms.

Finally, there is one more type of syncretism that applies to three of the declensions. Genitive singular and nominative plural are syncretised in the non-feminine ( $-\mathrm{F})$ declensions ( $o$-, $u$-declension, excepting neuters, of course) and also in the $a$ declension. This instance of syncretism is indicated by double lines in the diagram whereas single lines indicate distinctness. ${ }^{11}$

As the inspection of Fig. 2 reveals, syncretisms are not distributed at random over declensions and paradigms. Patterns of non-distinctness correlate with the divisions of declensions with respect to genders and parts of speech. As might be expected, the differentiation of case forms is better developed in the singular as compared to the plural and in non-oblique cases as compared to oblique cases. Thus, incidence of syncretism increases along the case-number-scale. Perhaps more surprisingly, it

\footnotetext{
${ }^{11}$ This type of syncretism $(\mathrm{GSg}=\mathrm{NPl})$ is also found in other Indo-European languages, e.g., in Greek and Russian; for discussion see Johnston (1997: Sect. 2.4.1) and also Stump (2001: 171, 229, 239) and Wunderlich (2004: Sect. 4). According to Johnston (1997: 102) this syncretism is systematic though 'inherently unrepresentable' within his model of Paradigm Geometry. The same would seem to hold for models using underspecification.
} 
Table 2 Sequences of syncretism fields

\begin{tabular}{|c|c|c|c|c|c|c|c|c|c|c|c|c|}
\hline & $\mathrm{V}$ & $\mathrm{N}$ & A & $\mathrm{Ab}$ & $\mathrm{D}$ & G & $\mathrm{V}_{\mathrm{Pl}}$ & $\mathrm{N}_{\mathrm{Pl}}$ & $\mathrm{A}_{\mathrm{PL}}$ & $\mathrm{Ab}_{\mathrm{PL}}$ & $\mathrm{D}_{\mathrm{PL}}$ & $\mathrm{G}_{\mathrm{PL}}$ \\
\hline ictus, $u$-decl. & \multicolumn{2}{|c|}{$\mathrm{VN}$} & A & $\mathrm{Ab}$ & $\mathrm{D}$ & \multicolumn{4}{|c|}{$\mathrm{G} V \mathrm{NA}_{\mathrm{Pl}}$} & \multicolumn{2}{|c|}{$\mathrm{AbD}_{\mathrm{Pl}}$} & $\mathrm{G}_{\mathrm{Pl}}$ \\
\hline rēgs, $C$-decl. & \multicolumn{2}{|c|}{$\mathrm{VN}$} & A & $\mathrm{Ab}$ & $\mathrm{D}$ & $\mathrm{G}$ & \multicolumn{3}{|c|}{$\mathrm{VNA}_{\mathrm{Pl}}$} & \multicolumn{2}{|c|}{$\mathrm{AbD}_{\mathrm{Pl}}$} & $\mathrm{G}_{\mathrm{Pl}}$ \\
\hline diēs, e-decl. & \multicolumn{2}{|c|}{$\mathrm{VN}$} & A & $\mathrm{Ab}$ & \multicolumn{2}{|c|}{ DG } & \multicolumn{3}{|c|}{$\mathrm{VNA}_{\mathrm{Pl}}$} & \multicolumn{2}{|c|}{$\mathrm{AbD}_{\mathrm{Pl}}$} & $\mathrm{G}_{\mathrm{Pl}}$ \\
\hline capra, a-decl. & \multicolumn{2}{|c|}{$\mathrm{VN}$} & A & $\mathrm{Ab}$ & \multicolumn{4}{|c|}{$\mathrm{DG} \mathrm{VN}_{\mathrm{Pl}}$} & $\mathrm{A}_{\mathrm{Pl}}$ & \multicolumn{2}{|c|}{$\mathrm{AbD}_{\mathrm{Pl}}$} & $\mathrm{G}_{\mathrm{Pl}}$ \\
\hline ignis, $i$-decl. & \multicolumn{2}{|c|}{$\mathrm{VN}$} & A & \multicolumn{2}{|c|}{$\mathrm{AbD}$} & $\mathrm{G}$ & \multicolumn{2}{|c|}{$\mathrm{VN}_{\mathrm{Pl}}$} & $\mathrm{A}_{\mathrm{Pl}}$ & \multicolumn{2}{|c|}{$\mathrm{AbD}_{\mathrm{Pl}}$} & $\mathrm{G}_{\mathrm{Pl}}$ \\
\hline lupus, o-decl. & $\mathrm{V}$ & $\mathrm{N}$ & A & \multicolumn{2}{|c|}{$\mathrm{AbD}$} & \multicolumn{3}{|c|}{$\mathrm{G} \mathrm{VN}_{\mathrm{Pl}}$} & $\mathrm{A}_{\mathrm{Pl}}$ & \multicolumn{2}{|c|}{$\mathrm{AbD}_{\mathrm{Pl}}$} & $\mathrm{G}_{\mathrm{Pl}}$ \\
\hline
\end{tabular}

can be seen now that systematic syncretism always applies to contiguous sections of the case-number-scale. (Apparent counterexamples will be discussed in Sect. 3.2, below.) As a further illustration of this finding Table 2 shows the division of paradigms into syncretism fields for six sample nouns. (In the table, abbreviated names of plural cases are formed using a subscript 'Pl' while unsubscripted abbreviations refer to singular cases.) It turns out that there are six different sequences of syncretism fields for the six different declensions (if neuters are ignored). But note that these six different patterns are all based on systematic syncretisms, which apply across declensions but are combined differently in each of the declensions. As a result, regular noun paradigms in Latin are rather compact, including as they do seven to eight syncretism fields (for neuters: six to seven), that is, six, seven, or eight distinct word forms for twelve case-number combinations.

\section{Formal categories}

\subsection{Types of endings}

The central question to be answered in this investigation is how are the various endings distributed over cells of paradigms? The set-up visible from Fig. 2 does not match the ideal derived from classical morphemic analysis. Consider for instance the endings of the three oblique cases of the singular. Each of the morphemes that might be assumed would have five or six allomorphs, some of them quite dissimilar in phonological form. A majority of these allomorphs would belong to two of the three morphemes, the long $\bar{l}$ to all three. Depending on the declension, this $\bar{l}$ marks the dative, the genitive, or the ablative and the dative; it additionally appears with nominative plurals. A morpheme-based analysis leads us into a web of homonymies and synonymies, yet no underlying 'logic' ever becomes apparent. ${ }^{12}$

\footnotetext{
${ }^{12}$ It is not obvious that more refined morphemic models could do better than that (cf. below, Sect. 4). Halle and Vaux (1998) postulate a vocabulary of eight underspecified items from which Latin endings could be
} 
In order to make some progress, I shall propose a classification of the endings based on form-related properties. As for the general procedure of analysis, two moves are important. First, theme vowels can be factored out, as it were, from the endings (see Kiparsky 2000: Sect. 5, on Gothic). Being determined by declension class, theme vowels do not contribute to the differentiation of inflectional forms within paradigms. Put differently, the quality of the theme vowel in a word form like capram is triggered by the stem, not by the ending. Thus, the ending in capram may be represented as - $V m$ (where ' $V$ ' represents the theme vowel) the ending being spelled out as -am if applied to an $a$-declension noun such as capra.

Second, endings may be analysed in terms of recurrent similarities. This leads to a view of endings as involving more basic elements or 'markers'. ${ }^{13}$ As pointed out by Jakobson (1965: 353), "the search for the connection between the signans and signatum of the grammatical morphemes must involve not only the instances of their complete formal identity, but also such situations where different affixes share a certain grammatical function and one constant feature." For illustration Jakobson referred to the distribution of the nasality feature as occurring in endings of so-called marginal cases (instrumental, dative, locative) in Polish and Russian. In Latin, two markers stand out as constituting the very core of the system of nominal marking, namely the desinential consonants $s$ and $m .{ }^{14}$

Within the overall system of six cases and two numbers a basic subsystem may be singled out in terms of functional markedness. This subsystem comprises the non-oblique cases of the non-plural, hence the vocative, nominative and accusative singular, and it is within this subsystem that we encounter basic markers. Consider the fourth declension, where the relevant endings are $-u,-u s$, and -um. Abstracting away the theme vowel $u$, one may note that the unspecific (non-oblique) forms of the neuter are left unmarked, the ending being $-u$ (bare theme vowel). With non-neuters, vocative-nominative forms show $s$, accusative forms show $m$. Thus, $-u,-u s$ and -um may be assigned to three classes of endings: non-consonantal endings, $s$-endings (traditionally, 'sigmatic endings'), and $m$-endings ('nasal endings'). Other declensions use the same markers for the same subsystem of non-oblique non-plural cases, hence all non-oblique non-plural endings exhibit the consonantal markers alluded to or no markers at all.

The overall declensional system may be regarded as an extension of the unmarked subsystem that is arrived at by adding oblique cases and the plural. What is more, endings of the extended system may be construed as complex counterparts of the basic ones, and they may be classified into the same three classes.

built up using the techniques available in Distributed Morphology. However, to make their system work, they have to rely on a set of case-features that are left without serious justification as well as on a battery of so-called rules of impoverishment (feature deletion rules) that seem completely ad hoc (for illustration, one of the rules they posit "deletes [-plural] in Nominative endings of [-neuter] nouns" (p. 228)). The explanatory value of this analysis remains dubious.

${ }^{13}$ Cf. Pike (1965) on the segmentation of morphemes into 'formatives' (with application to German inflection) as well as approaches to morphological subanalysis as represented in Müller and Trommer (2006), with references.

${ }^{14}$ Perhaps, these markers may be traced back to Proto-Indo-European "where two basic argument types, $*_{-}$os and *-om, expressed all the basic syntactic relations" according to Gamkrelidze and Ivanov (1995: 248 , and cf. p. 267 et passim). 
The class of sigmatic endings is the most developed one. It comprises five types of different complexity. As indicated, - us (as in ictus) includes the sigmatic marker only. Thus, $-u s$ is assigned to a type of ending represented as $\mathbf{s}$. In addition to the sigmatic marker, the ending -is (as in régis) includes a vowel that is not a theme vowel. Such vowels will be referred to as 'desinential vowels'. Occurrences of desinential vowels will be represented by $\mathbf{v}$ where markers are under discussion. Thus, -is belongs to the type vs. Next, the ending $-\bar{u} s$ (as in $i c t \bar{u} s$ ) contains a long theme vowel. The length of the theme vowel is significant while the quality of the theme vowel is not. For this reason, I identify a marker constituted by vowel length, which is represented as L. Thus, $-\bar{u} s$ belongs to the type Ls. Marking by length and by desinential vowel may combine. E.g., - $\bar{l} s$ (as in lupiss) exhibits a long non-thematic vowel. This ending belongs, then, to the type vLs.

Types can be ranked by complexity. For convenience, endings belonging to the simple type s will be termed 'light endings', while those belonging to the complex types vs, Ls, and vLs will be termed 'heavy'. Obviously, vLs is more complex than either vs or Ls. The question may be left open how a relative ranking of vs and Ls could be justified if needed. There is one more type of sigmatic endings exemplified by -ibus (as in ictibus). This ending exhibits an extra 'insert' (viz. bu) that adds extra complexity. For present purposes, the type of sigmatic endings showing an insert may be represented somewhat simplified as -X-s.

Similarly, the class of non-consonantal endings splits into types of different complexity. The ending - $a$ (as in capra) is made up of a (non-lengthened) theme vowel. It is non-consonantal and, moreover, it includes neither $\mathbf{v}$ nor $\mathbf{L}$. Thus it belongs to the light type of non-consonantal endings. Non-consonantal endings, too, may exhibit desinential (i.e., non-thematic) vowels as, e.g., -e (as in rēge). This ending belongs to the type $\mathbf{v}$. Next, the ending $-\bar{u}$ (as in $i c t \bar{u}$ ) contains a long theme vowel (but no consonant). This ending belongs to type $L$. And again, there are endings that contain a long desinential vowel, e.g., $-\bar{l}$ as in lup $\bar{l}$. The ending $-\bar{l}$ belongs, then, to type vL. There are no non-consonantal endings that show inserts.

The class of nasal endings ( $m$-endings) comprises only three types. The ending -am (as in capram) includes the nasal marker only (apart from the theme vowel). Thus, - am is assigned to a type of ending represented as $\mathbf{m}$. In addition to the nasal marker, the ending -ium (as in ignium) includes a desinential (non-thematic) vowel, viz. $u$, in addition to the theme vowel $i$. Thus, -ium belongs to the type vm. There are also nasal endings that exhibit an extra 'insert' (viz. ru, e.g., -ārum as in caprārum). And again, for present purposes, the type of nasal endings showing an insert may be represented somewhat simplified as $\mathbf{- X} \mathbf{- m}$.

Table 3 presents an overview of the types of endings that have been assumed. The bottom row provides examples for each type of ending. Patterns that are instantiated by the respective endings are given above. In pattern representation ' $\mathrm{V}$ ' represents a theme vowel, and ' $v$ ' represents a desinential vowel, i.e., a vowel that is not a theme vowel. The marker row identifies combinations of markers that constitute the various types of endings as explained above. Numerical labels are given for ease of reference. The headers of the table give the names of classes of endings as introduced before. The order of types reflects formal markedness. Both light and heavy endings include three classes (non-consonantal, sigmatic and nasal endings). Types within classes 


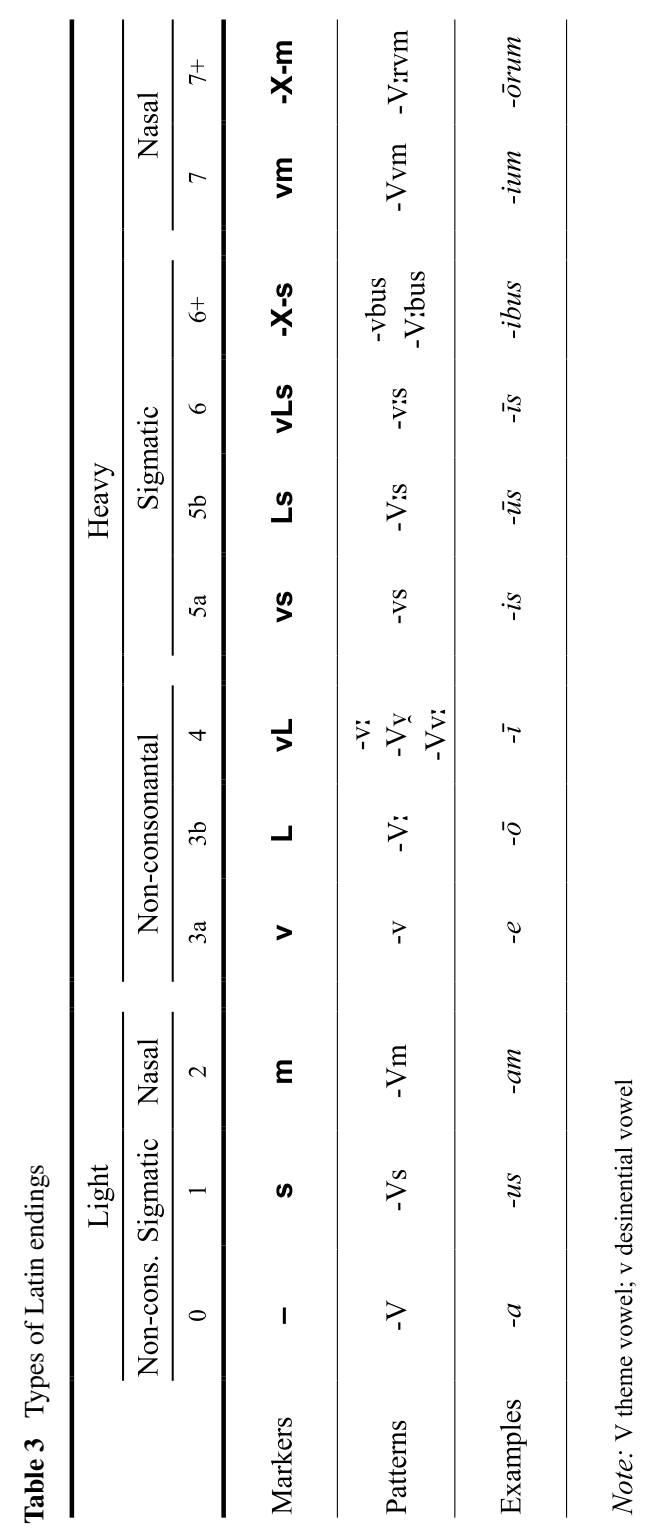


differ in complexity as indicated above. Non-consonantal endings (including endings without markers) can safely be taken to be less marked than consonantal endings of comparable complexity but a formal basis for the relative ranking of the two classes of consonantal endings is not obvious. Still, the reduced number of subtypes within the nasal class as compared to the sigmatic class may point to the more 'marginal' status of nasal endings alluded to by Jakobson.

Forms of the vocative/nominative/accusative plural neuter are special (cf. Leumann 1977: 452). Across declensions, they exhibit endings in $a$ that may or may not include a theme vowel (as in iuga, maria, nomina, genua). These endings are outside of the general series and, therefore, are not represented in Table 3.

As for the numbering of types, it may be noted that:

- endings of types 7 and 7+ are in complementary distribution, that is, there is no paradigm that includes endings of both types. Declensions that possess non-close theme vowels (i.e., $a, o$, or $\bar{e}$ ) employ endings of the type -X-m (as in caprārum, lupōrum, and dierrum) while the remaining declensions employ endings of the type -vm (cf. the genitive plural forms ignium, rēgum, and ictuum)

- endings of types 6 and $6+$ are also in complementary distribution. The $a$ declension and the $o$-declension lack endings of the type -X-s. The remaining declensions possess such endings (as in ignibus, rēgibus, ictibus, and diēbus)

- endings of types $3 \mathrm{a}$ and $3 \mathrm{~b}$ are also in complementary distribution. In fact, endings of types $3 \mathrm{a}$ and $5 \mathrm{a}$ appear only in the 3rd declension.

As an interim result, it may be observed that the endings of Latin nominal inflection instantiate a limited set of types, which are made up from an even more limited set of elementary components ('markers') in a rather transparent way.

\subsection{Vocalism of endings}

Before turning to the form-function-relationship I shall add some comments on matters of detail pertaining in particular to the vocalism of endings. Examples are provided in Table 4 and will be commented on in the order of the numbering given in the table.

(1) Length of the theme vowel is significant; cf., e.g., the forms of the nominative and ablative singular of the $a$-declension. The ending of the vocative/nominative/ accusative singular neuter of the $u$-declension is assumed to be $-u$ (short theme vowel) as in Risch (1977) based on the convincing demonstration in Leumann (1977: 441) (whereas school grammars traditionally give $-\bar{u}$ ). ${ }^{15}$

(2) Various endings of the ablative singular consist of a lengthened theme vowel. In terms of markers, they have identical representations, viz. L. In the 5th declension lengthening applies vacuously, as the theme vowel is long $\bar{e}$.

(3) Vowels immediately preceding word-final $m$ are short. Hence, the long theme vowel $\bar{e}$ of the 5th declension is shortened in this position (Leumann 1977: 225, 441).

\footnotetext{
${ }^{15}$ As Janson (1971: 137) confirms, the type cornu "is but an apparent exception" to the generalization that "there are no instances of syncretism between the forms for nominatives (or accusatives) and the forms for datives (or ablatives)".
} 
Table 4 Examples of endings and analyses

\begin{tabular}{|c|c|c|c|c|}
\hline & & ending & pattern & marker \\
\hline \multirow[t]{2}{*}{ (1) } & cornu, VNASgNtr, V=u & $-u$ & $-\mathrm{V}$ & - \\
\hline & $i c t \bar{u}, \mathrm{AbSg}, \mathrm{V}=u$ & $-\bar{u}$ & $-\mathrm{V}:$ & $\mathbf{L}$ \\
\hline \multirow[t]{4}{*}{ (2) } & lup $\bar{o}, \mathrm{AbSg}, \mathrm{V}=o$ & $-\bar{o}$ & $-V:$ & $\mathbf{L}$ \\
\hline & ignī, $\mathrm{AbSg}, \mathrm{V}=i$ & $-\bar{l}$ & $-V:$ & $\mathbf{L}$ \\
\hline & $i c t \bar{u}, \mathrm{AbSg}, \mathrm{V}=u$ & $-\bar{u}$ & $-\mathrm{V}:$ & $\mathbf{L}$ \\
\hline & $d i \bar{e}, \mathrm{AbSg}, \mathrm{V}=\bar{e}$ & $-\bar{e}$ & $-\mathrm{V}:$ & $\mathbf{L}$ \\
\hline \multirow[t]{2}{*}{ (3) } & capram, $\mathrm{ASg}, \mathrm{V}=a$ & $-a m$ & $-\mathrm{Vm}$ & m \\
\hline & diem, $\mathrm{ASg}, \mathrm{V}=\breve{e}(<\bar{e})$ & $-e m$ & $-\mathrm{Vm}$ & m \\
\hline \multirow[t]{3}{*}{ (4) } & lupe, $\mathrm{VSg}, o$-dec., $\mathrm{V}=\mathrm{e}$ & $-e$ & $-\mathrm{V}$ & - \\
\hline & lupus, $\mathrm{NSg}, o$-dec., $\mathrm{V}=u$ & $-u s$ & $-\mathrm{Vs}$ & $\mathbf{s}$ \\
\hline & lup $\bar{o}, \mathrm{AbSg}, o$-dec., $\mathrm{V}=o$ & $-\bar{O}$ & $-V:$ & $\mathbf{L}$ \\
\hline \multirow[t]{4}{*}{ (5) } & caprīs, $\mathrm{AbP} 1, \mathrm{v}=i$ & $-\bar{l} S$ & $-v: S$ & vLs \\
\hline & lupīs, $\mathrm{AbPl}, \mathrm{v}=i$ & $-\bar{l} s$ & -v:s & vLs \\
\hline & ignium, $\mathrm{GP} 1, \mathrm{~V}=i, \mathrm{v}=u$ & -ium & $-V v m$ & vm \\
\hline & ictuum, $\mathrm{GPl}, \mathrm{V}=u, \mathrm{v}=u$ & $-u u m$ & $-\mathrm{Vvm}$ & $\mathbf{v m}$ \\
\hline \multirow[t]{2}{*}{ (6) } & mare, VNASgNtr, $\mathrm{V}=e(<i)$ & $-e$ & $-\mathrm{V}$ & - \\
\hline & rēge, $\mathrm{AbSg}, \mathrm{v}=e(<i)$ & $-e$ & $-\mathrm{V}$ & $\mathbf{v}$ \\
\hline \multirow[t]{2}{*}{ (7) } & ignis, $\mathrm{NSg}, \mathrm{V}=i$ & $-i s$ & $-\mathrm{Vs}$ & $\mathbf{s}$ \\
\hline & rēgis/ignis, GSg, $\mathrm{v}=i$ & $-i s$ & -vs & vs \\
\hline \multirow[t]{2}{*}{ (8) } & $r \bar{e} s, \mathrm{NSg}, \mathrm{V}=\bar{e}$ & $-\bar{e} S$ & $-\mathrm{Vs}$ & $\mathbf{s}$ \\
\hline & $r \bar{e} s, \mathrm{NPl}, \mathrm{V}=\bar{e}$ & $-\bar{e} S$ & -Vis & Ls \\
\hline \multirow[t]{3}{*}{ (9) } & lup $\bar{l}, \mathrm{GSg}, o$-dec., $\mathrm{v}=i$ & $-\bar{l}$ & -v: & $\mathbf{v L}$ \\
\hline & caprae, GDSg, $a$-dec., $\mathrm{v}=i$ & $-a e$ & $-V \underline{v}$ & $\mathbf{v L}$ \\
\hline & $i c t u \bar{\imath}, \mathrm{DSg}, u$-dec., $\mathrm{v}=i$ & $-u \bar{\imath}$ & $-V v:$ & $\mathbf{v L}$ \\
\hline
\end{tabular}

(4) In the $o$-declension, the theme vowel varies. The theme vowel is close if short, viz. $u$ (as in lupum as opposed to lupō); see Leumann (1977: 94, 441) on $o>u$ in inflectional endings. In addition, there is a relic of $e / o$-ablaut as in lupe, vocative singular (Leumann 1977: 408).

(5) By default, the desinential vowel is $i$. When adjacent to $m$ (the labial nasal) the desinential vowel is $u$. 
(6) Short $i$ in word-final position changes to $e$ (Leumann 1977: 92). This applies to the theme vowel (as in mare, non-oblique singular neuter, $i$-declension) as well as to the desinential vowel (as in $r \bar{e} g e$, ablative singular, $C$-declension). As a consequence, the ending written $-e$ is ambiguous and receives two distinct analyses.

(7) The ending of the nominative singular form ignis ( $i$-dec.) includes the theme vowel $i$, while the ending of the genitive singular form (also ignis) includes the desinential vowel $i$ as may be seen by comparing corresponding forms from the $C$-declension, e.g., $r \bar{e} g s$, nominative singular, and $r \bar{e} g i s$, genitive singular. ${ }^{16}$ Thus, the ending written -is (as in ignis) is ambiguous, too. The forms in question receive distinct morphological analyses where the endings belong to the types $\mathbf{s}$ and vs, respectively. These endings are not identical from a morphological point of view as would be required for a proper case of systematic syncretism. This finding conforms to the result of the analysis in Carstairs (1987: 99f.).

(8) The ending of the nominative singular form rēs includes the theme vowel $\bar{e}$, which is long. At the same time, the ending of the nominative-accusative plural form (also $r \bar{e} s$ ) instantiates the pattern of a lengthened theme vowel where lengthening applies vacuously (cf. (1), above). This may be seen by comparing the nominativeaccusative form ictūs from the $u$-declension. Again, this homonymy does not constitute a case of syncretism. The relevant types of endings are $\mathbf{s}$ and Ls, respectively. ${ }^{17}$

(9) Endings of type 4 show varying patterns. By definition, endings of this type combine the markers $\mathbf{v}$ and $\mathbf{L}$, thus this type subsumes long ( 2 or 3 morae) patterns that include the desinential vowel $i$ and may or may not include the theme vowel. Instances may be monophthongal (as $-\bar{\imath}$ in $l u p \bar{\imath}$ ) or diphthongal (as -ae in caprae, to be pronounced approximately as [aI], Leumann 1977: 18) or there may be variation between monophthongal and diphthongal realisations (as in the case of -ei). Following Leumann (1977: 447) and Risch (1977: $231 \mathrm{n} .6)-e i$ is assumed to be monosyllabic during the late republican era, the monophthongal variant being pronounced as $-\bar{\imath}$. (School grammars traditionally give $-\bar{e} \bar{\imath}$ or $-e \bar{l}$.)

\section{Form-function relationship}

In the above, I have discussed Latin noun inflections both from a functional and from a formal point of view. On the functional side, I have identified a markedness scale that provides a ranking of case-number-combinations from vocative singular (unmarked) to genitive plural (most marked). Moreover, it has been seen that in any given declension the number of positions that are differentiated formally is reduced by syncretisms, which collapse contiguous sections of the scale. Thus for any given declension there is a sequence of syncretism fields as exemplified in Table 2. On the

\footnotetext{
${ }^{16}$ The desinential vowel $i$ in sigmatic endings of genitive singular forms may also be seen in the $u$ declension (where it could not be mistaken for a theme vowel), namely in alternative variants ('by-forms') such as senātuis (Leumann 1977: 441f., "bemerkenswerte Nebenformen").

${ }^{17}$ Nouns like nūbēs 'cloud', 3rd declension, also show homonymy of nominative singular and plural forms in $-\bar{e} s$. According to Janson (1971: 119) these nouns are "on the borderline between the traditional fifth and third declensions" and use of the ending -ēs with these nouns is "outside the ordinary rules".
} 
Table 5 Correlation of formal and functional sequences ( $u$-declension)

\begin{tabular}{lcccccccc}
\hline Types & 0 & $\mathbf{1}$ & $\mathbf{2}$ & 3 & 4 & 5 & $6+$ & 7 \\
\hline Markers & - & $\mathbf{s}$ & $\mathbf{m}$ & $\mathbf{L}$ & $\mathbf{v L}$ & $\mathbf{L s}$ & $\mathbf{- X}-\mathbf{s}$ & $\mathbf{v m}$ \\
\hline Endings & $-u$ & $-u s$ & $-u m$ & $-\bar{u}$ & $-u \bar{l}$ & $-\bar{u} s$ & $-i b u s$ & $-u u m$ \\
\hline Fields & $\mathrm{VNA}_{\mathrm{Ntr}}$ & $\mathrm{VN}$ & $\mathrm{A}$ & $\mathrm{Ab}$ & $\mathrm{D}$ & G VNA $_{\mathrm{Pl}}$ & $\mathrm{AbD}_{\mathrm{Pl}}$ & $\mathrm{G}_{\mathrm{Pl}}$ \\
\hline
\end{tabular}

$\mathrm{VNA}_{\mathrm{NtrPI}}$ not included

formal side, I have identified a markedness scale that provides a ranking of types of endings from unmarked (no markers) to most marked (heavy nasal endings) given in Table 3 .

On this basis, the form-function-relationship in Latin noun inflection may be clarified. In any declension, the form-function-relationship is established by aligning the formal sequence and the relevant functional sequence. For illustration, consider the $u$-declension. The alignment of the formal sequence and the relevant functional sequence is shown in Table $5 .{ }^{18}$

Setting apart the non-oblique neuter plural ending, there are eight syncretism fields (or 'fields', for short) in the $u$-declension. The endings assigned to these eight fields belong to the types 0 to 7 . The alignment is iconic in that the relative positions of types of endings in the formal sequence correspond to the relative positions of the respective fields in the functional sequence as should be obvious from an inspection of Table 5. Thus, formal and functional markedness increase in tandem from the markerless non-oblique singular neuter forms to the genitive plural forms that show a heavy nasal ending.

The form-function-relationship in the remaining declensions is established in the same way. Table 6 presents the correlation of formal and functional sequences in all declensions excepting the 3rd, which calls for some additional comments. Table 6 is to be read in the same way as explained for Table 5. Again, the form-functionrelationship is simple and patently iconic.

A remark may be added concerning the variation between declensions regarding the usage of forms of type 0 and 1 . Feminine $(+\mathrm{F})$ declensions $(a-, \bar{e}$-declension) use either an ending of type 0 or an ending of type 1 for both vocative and nominative singular. The remaining declensions including the $3 \mathrm{rd}$ declension use endings of both types. Endings of type 0 appear in non-oblique singular forms of neuters while endings of type 1 occur in the vocative and nominative of non-neuters. The $o$-declension deviates by using the type 0 ending $(-e)$ not with neuters but in the vocative of non-neuters, this being the only non-syncretised form of the vocative. In non-oblique singular neuter forms the ending of the accusative non-neuter (type 2) stands in.

\footnotetext{
${ }^{18}$ For some discussion of the importance of such alignments or 'projections' ('Abbildungen') between independently established sequences (or 'series') from the point of view of the psychology of language see Bühler (1990: 216f. [1934: 192f.]). Using Bühler's terms, one order (in the present case, the functional case-number order) "is projected image-like on the associational order" (ibid.), which in the present case is constituted by the ranked sequence of endings. Thus, contiguity of positions on a functional scale "recurs in the contiguous character of the associational series" (ibid.).
} 


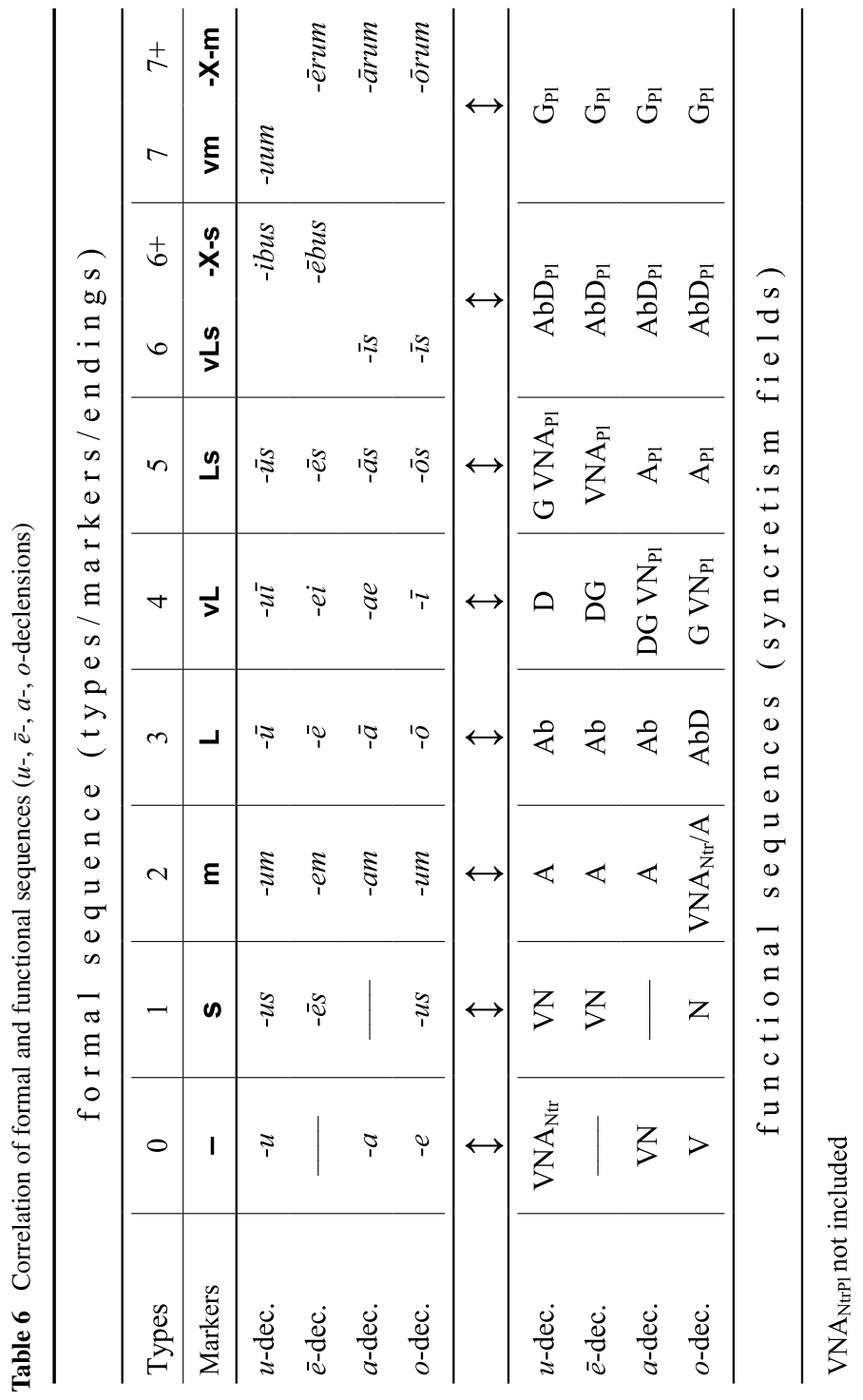


Table 7 Correlation of formal and functional sequences ( $C$-, $i$-declensions)

\begin{tabular}{lccccccccc}
\hline Types & 0 & 1 & 2 & $3 \mathrm{a} / \mathrm{b}$ & 4 & $5 \mathrm{a}$ & $5 \mathrm{~b}$ & $6+$ & 7 \\
\hline Markers & - & $\mathbf{s}$ & $\mathbf{m}$ & $\mathbf{v / L}$ & $\mathbf{v L}$ & $\mathbf{v s}$ & $\mathbf{L s}$ & $\mathbf{X}-\mathbf{s}$ & $\mathbf{v m}$ \\
\hline$C$-dec. & - & $-s$ & $-e m$ & $-e$ & $-\bar{l}$ & $-i s$ & $-\bar{e} s$ & $-i b u s$ & - \\
\hline$i$-dec. & $-e$ & $-i s$ & $(-i m)$ & $(-\bar{\imath})$ & & & & \\
\hline Fields & $\mathrm{VNA}_{\mathrm{Ntr}}$ & $\mathrm{VN}$ & $\mathrm{A}$ & $\mathrm{Ab}$ & $\mathrm{D}$ & $\mathrm{G}$ & $\begin{array}{c}\mathrm{NA}) \\
\left(\mathrm{A}_{\mathrm{Pl}}\right)\end{array}$ & $\mathrm{AbD}_{\mathrm{Pl}}$ & $\mathrm{G}_{\mathrm{Pl}}$ \\
\hline
\end{tabular}

$\mathrm{VNA}_{\mathrm{NtrPl}}$ not included

The synopsis of the four declensions in Table 6 reveals an important property of the form-function-relationship that could not be seen by consideration of a single declension. Some types of endings are in one-to-one correspondence with bundles of morphosyntactic properties as they should be according to a classical morphemic approach. For instance, type 7/7+ endings appear in all forms of the genitive plural and only in such forms; also, type 6/6+ endings appear in all forms of the ablative-dative plural and only in such forms. However, type 5 endings may occur in forms of different cases in different declensions. It is true that accusative plural forms always take type 5 endings, but endings of this type may also appear in the vocative-nominative plural and moreover in the genitive singular. Similar remarks apply to the remaining endings.

Nevertheless, endings of type 5 can be assigned a uniform role if the form-function relationship is understood to be based on an alignment of formal and functional sequences as described above. As can be read off Table 6, in all four declensions, type 5 endings appear with forms that occupy the third field in functional sequences, counting from the right, regardless of which case-number combinations are covered by this field. Similarly, endings of type 4 are used with forms that occupy the next highest field (which may cover cases from dative singular up to nominative plural depending on declension), and so on.

Within the 3rd declension, the form-function relationship does not deviate from the general pattern as will be seen from Table 7. However, this declension is notorious for its complexity, so some discussion is required. The $3 \mathrm{rd}$ declension comprises a number of paradigms (including those of $r \bar{e} g s, C$-dec., and ignis, $i$-dec. as in Table 1) that show overlapping selections from the inventory of endings given in Table 7.

The endings of the dative singular, the genitive singular and the ablative-dative plural apply uniformly across paradigms of the 3rd declension. However, the distinction between $i$-declension and $C$-declension becomes apparent with the remaining endings. For example, the genitive plural ending (type 7) of the $i$-declension (viz. -ium) exhibits the theme vowel $i$, which is missing in the corresponding ending of the $C$-declension (viz. -um). An analogous distinction is seen in types 0 and 1 (and also in the neuter plural endings $-a$ vs. $-i a$ ). There are also endings in $i$ that appear in the accusative singular, the ablative singular and the accusative plural, viz. $-i m,-\bar{l}$, and $-\bar{l} s$, respectively, but these tend to be replaced by their non- $i$-counterparts (and 
are put in parentheses therefore in Table 7). The accusative singular ending -im, in particular, has very restricted use while $-\bar{l}$ and $-\bar{l} s$ are relatively better preserved.

Traditional grammars distinguish a number of subtypes of the 3rd declension in order to account for the usage made of these three endings. ${ }^{19}$ These endings are not used at all with 'consonant stems' like rēgs whereas so called ' $i$-stems', e.g., ignis, exhibit both $-\bar{l}$ and $-\bar{l} s$. (Thus, ablative and dative singular forms coincide in the $i$ declension.) The class of ' $i$-stems' also includes a rather restricted group of nouns like turris 'tower' that allow accusatives in -im and for some of these nouns (like sitis 'thirst') endings in $i$ may even be obligatory ('pure $i$-stems'). In addition to $C$ stems and $i$-stems, there are 'mixed $i$-stems' like $u r b s$ 'city' that take only $-\bar{l} s$ from among the three. Neuter $i$-stem nouns (which take $-e$ in the non-oblique singular) always preserve ablatives in $-\bar{l}$, for reasons of homonymy avoidance (Janson 1971: 139; Risch 1977: 244): a non-distinctness across the non-oblique-oblique boundary is not tolerated, as it were (cf. Janson 1971: 137). Similarly, adjectives prefer forms in $i .^{20}$

The absence of a theme vowel with $C$-stems has various repercussions on the make-up of endings. If possible, the expected position of the theme vowel may simply be empty as indicated above (cf. - um vs. -ium). Otherwise, the vowel $e$ may stand in as in -em, type 2, where em developed from vocalic $m$ (collapsing with $\mathrm{em}<\mathrm{im}$ ), or in $-\bar{e} s$ (type 5b), for which see Leumann (1977: 436). More interestingly, endings that include a desinential vowel may take over. A comparison of the $C$-declension and the $u$-declension is instructive. In the plural both declensions show identical markers. In the singular, however, the presence vs. absence of a theme vowel is reflected by a characteristic difference. While ablative and genitive singular forms of the $u$ declension exhibit endings of types $\mathbf{L}(3 \mathrm{~b})$ and $\mathbf{L} \mathbf{s}(5 \mathrm{~b})$, respectively, the $C$-declension has forms with endings of type $\mathbf{v}(3 \mathrm{a})$ and vs (5a) instead. Here, endings including a desinential vowel (as in $r \bar{e} g-e$ and $r \bar{e} g-i s$ ) are employed where otherwise lengthening of a theme vowel would be called for (as in $i c t-\bar{u}$ and $i c t-\bar{u} s$ ).

As formal and functional sequences are aligned, a remarkable form-function relationship is revealed that could not be captured in a classical morphemic approach. What is more, it appears that even refined morphemic conceptions that have been proposed within various theoretical approaches would fail including those that allow for underspecification. What unites the domains of application of, say, type 5 endings across different declensions is the position of the correlated syncretism field (third highest) in functional sequences. It is anything but obvious that this information could be represented by a bundle of morphosyntactic features underspecified or not.

\footnotetext{
${ }^{19} \mathrm{~A}$ meticulously detailed description of the distribution of the endings of the 3rd declension is given in Janson (1971); see also Leumann (1977), Risch (1977) and Carstairs (1984). Wurzel (1984: 120) proposed to capture the implicational relations between endings (e.g., 'if accusative singular in -im, then accusative plural in $-\bar{l} s^{\prime}$ ) that have been pointed out in Janson (1971), Risch (1977) and Leumann (1977) in terms of 'paradigm structure conditions'. For critique and discussion see Nyman (1987), Carstairs-McCarthy (1991) and Dressler (2002).

${ }^{20}$ As confirmed by Janson (1971: 140), "Most of the stems that keep the $i$-stem endings throughout are adjectives, and most of the consonantal stems are nouns." The correlation between parts of speech and the subtypes of the 3rd declension is seen most clearly in the ablative singular: "the main groups of stems taking the endings $-e$ and $-\bar{l}$ are nouns and adjectives, respectively" (Janson 1971: 128); cf. also Leumann (1977: 435).
} 


\section{Conclusion}

The analysis of Latin inflection that has been proposed differs from familiar approaches in a number of respects. Traditionally, Latin nominal inflection is analysed as being based on uniformly structured paradigms, which encompass twelve positions combining six cases and two numbers. At the same time, the number of distinct word forms in a paradigm is always less than twelve. In fact, standard noun paradigms exhibit six to eight distinct word forms. This discrepancy between the number of forms and the number of cells in paradigms is a systematic one and has to be accounted for systematically in a proper account of Latin inflection. Traditional treatments have failed to do so.

I have argued that the twelve case-number-combinations which constitute Latin noun paradigms can be positioned on a scale of markedness. This is made possible if case systems are analysed as hierarchical classification systems. Contiguous sections of the scale are subject to syncretisms that are systematic but differ between declensions. As a consequence, paradigms do possess different internal structures, and these can be described in terms of sequences of syncretism fields (or functional scales).

From a traditional point of view, differences between declensions are mainly due to the employment of different sets of case-number endings, not to structural differences. But endings from different declensions show conspicuous similarities, and these can be accounted for if recurrent components (or markers) are given due consideration. The various endings of the five or six declensions may then be seen as instantiating a smaller number of types, and these types can be put into a ranked order (a formal scale) that applies across declensions.

Traditionally, the relationship between form and function is said to be arbitrary. However, if it is considered how formal and functional sequences are mapped onto each other in Latin noun paradigms a remarkable parallelism of formal and functional markedness is revealed, in fact, a near to perfect example of iconicity. The present analysis would seem to support the hypothesis that iconicity of form and function is to be acknowledged as a basic design feature of inflectional systems.

\section{References}

Alexiadou, A., \& Müller, G. (2008). Class features as probes. In A. Bachrach \& A. Nevins (Eds.), Inflectional identity (pp. 101-155). Oxford: Oxford University Press.

Baerman, M., Brown, D., \& Corbett, G. G. (2005). The syntax-morphology interface: a study of syncretism. Cambridge: Cambridge University Press.

Baldi, P. (1983). On some recent claims in morphological theory. General Linguistics, 23, 171-190.

Bierwisch, M. (1967). Syntactic features in morphology: general problems of so-called pronominal inflection in German. In To honor Roman Jakobson. Essays on the occasion of his seventieth birthday (Vol. I, pp. 239-270). The Hague: Mouton.

Blake, B. J. (2001). Case (2nd ed.). Cambridge: Cambridge University Press.

Bühler, K. (1990). Theory of language. The representational function of language. Amsterdam: Benjamins. [(1934): Sprachtheorie. Die Darstellungsfunktion der Sprache. Jena: G. Fischer.]

Carstairs, A. (1984). Paradigm economy in the Latin third declension. Transactions of the Philological Society, 1984, 117-137.

Carstairs, A. (1987). Allomorphy in inflexion. London: Croom Helm.

Carstairs-McCarthy, A. (1991). Inflection classes: two questions with one answer. In F. Plank (Ed.) (1991c) (pp. 213-253). 
Dressler, W. U. (2002). Latin inflection classes. In A. M. Bolkestein et al. (Eds.), Theory and description in Latin linguistics. Selected papers from the XIth international colloquium on Latin linguistics, Amsterdam, June 24-29, 2001 (pp. 91-110). Amsterdam: Gieben.

Gamkrelidze, T. V., \& Ivanov, V. V. (1995). Indo-European and the Indo-Europeans. Part I. Berlin: de Gruyter.

Gasperini, L. (1999). Diachrony and synchrony of the Latin ablative: concerning certain semantic roles. Diachronica, 16(1), 37-66.

Greenberg, J. H. (1966). Language universals. With special reference to feature hierarchies. The Hague: Mouton.

Halle, M., \& Vaux, B. (1998). Theoretical aspects of Indo-European nominal morphology: the nominal declensions of Latin and Armenian. In J. Jasonoff, H.C. Melchert, \& L. Oliver (Eds.), Mír curad. Studies in honor of Calvert Watkins (pp. 223-240). Innsbruck: Institut für Sprachwissenschaft.

Householder, F. W. (1947). Descriptive analysis of Latin declension. Word, 3, 48-58.

Jakobson, R. (1965). Quest for the essence of language. Diogenes, 51, 21-37. [Repr. in: R. Jakobson (1971): Selected writings II. Word and language. The Hague: Mouton].

Jakobson, R. (1984). Structure of the Russian verb. In R. Jakobson, Russian and Slavic grammar. Studies 1931-1981 (pp. 1-14). Berlin: Mouton.

Janson, T. (1971). The Latin third declension. Glotta, 49(1/2), 111-142.

Johnston, J. (1997). Systematic homonymy and the structure of morphological categories: some lessons from paradigm geometry. Diss, University of Sydney.

Joseph, B. D., \& Wallace, R. (1984). Latin morphology: another look. Linguistic Inquiry, 15, 319-328.

Kiparsky, P. (2000). Analogy as optimization: 'exceptions' to Sievers' law in Gothic. In A. Lahiri (Ed.), Analogy, levelling, markedness. Principles of change in phonology and morphology (pp. 15-46). Berlin: de Gruyter.

Kulikov, L. (2006). Case systems in a diachronic perspective. A typological sketch. In L. Kulikov, A. Malchukov, \& P. de Swart (Eds.), Case, valency and transitivity (pp. 23-47). Amsterdam: Benjamins.

Leumann, M. (1977). Lateinische Laut- und Formenlehre. Neuausgabe. München: Beck.

Matthews, P. H. (1991). Morphology (2nd ed.). Cambridge: Cambridge University Press.

Müller, G. (2004). On decomposing inflection class features: syncretism in Russian noun inflection. In Müller et al. (Eds.) (2004) (pp. 189-227).

Müller, G., Gunkel, L., \& Zifonun, G. (Eds.) (2004). Explorations in nominal inflection. Berlin: de Gruyter.

Müller, G., \& Trommer, J. (Eds.) (2006). Subanalysis of argument encoding in distributed morphology. Leipzig: Universität. (Linguistische Arbeitsberichte, Leipzig 84).

Nyman, M. (1987). Is the paradigm economy principle relevant? Journal of Linguistics, 23, 251-267.

Pike, K. (1965). Non-linear order and anti-redundancy in German morphological matrices. Zeitschrift für Mundartforschung, 32, 193-221.

Plank, F. (1991a). Of abundance and scantiness in inflection: a typological prelude. In F. Plank (Ed.) (1991c) (pp. 1-39).

Plank, F. (1991b). Rasmus Rask’s dilemma. In F. Plank (Ed.) (1991c) (pp. 161-196).

Plank, F. (Ed.) (1991c). Paradigms. The economy of inflection. Berlin: de Gruyter.

Primus, B. (1993). Syntactic relations. In J. Jacobs, A. von Stechow, W. Sternefeld, \& T. Vennemann (Eds.), Syntax. An international handbook of contemporary research (Vol. 1, pp. 686-705). Berlin: de Gruyter.

Risch, E. (1977). Das System der lateinischen Deklinationen. Cahiers Ferdinand de Saussure, 3, $229-245$.

de Saussure, F. (1976). Cours de linguistique générale. Édition critique préparée par Tullio de Mauro. Paris: Payot.

Stump, G. T. (2001). Inflectional morphology. A theory of paradigm structure. Cambridge: Cambridge University Press.

Wiese, B. (2004). Categories and paradigms. On underspecification in Russian declension. In Müller et al. (Eds.) (2004) (pp. 321-372).

Wiese, B. (2011). Optimal specifications: on case marking in Polish. In A. Nolda \& O. Teuber (Eds.), Syntax and morphology multi-dimensional (pp. 101-127). Berlin: de Gruyter.

Williams, E. (1981). On the notions 'Lexically related' and 'Head of a word'. Linguistic Inquiry, 12, 245274.

Wunderlich, D. (2004). Is there any need for the concept of directional syncretism? In Müller et al. (Eds.) (2004) (pp. 373-395).

Wurzel, W. U. (1984). Flexionsmorphologie und Natürlichkeit. Ein Beitrag zur morphologischen Theoriebildung. Berlin: Akademie-Verlag. 